\title{
Estimation of Fetal Size and Weight using Various Formulas
}

\author{
Dr. Pushpamala Ramaiah1, Dr. Lamiaa Ahmed Elsayed², Dr. Grace Lindsey1, Dr. Ayman Johargy ${ }^{3}$ \\ 1Professor at Faculty of Nursing, Umm-Al-Qura University, KSA \\ ${ }^{2}$ Professor of pediatric Nursing, Ain Shams University and \\ 2Professor Faculty of Nursing Umm-Al Qura University, Makkah \\ ${ }^{3}$ Associate professor of Medical Microbiology, Faculty of Medicine, Umm Al-Qura University
}

\begin{abstract}
How to cite this paper: Dr. Pushpamala Ramaiah | Dr. Lamiaa Ahmed Elsayed | Dr. Grace Lindsey | Dr. Ayman Johargy "Estimation of Fetal Size and Weight using Various Formulas" Published in International Journal of Trend in Scientific Research and Development (ijtsrd), ISSN: 24566470, Volume-3 | Issue-3 , April 2019, pp.991-994, URL: https://www.ijtsrd.c om/papers/ijtsrd23 231.pdf

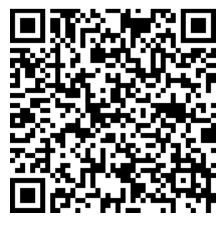
IITSRD23231
\end{abstract}

Copyright (C) 2019 by author(s) and International Journal of Trend in Scientific Research and Development Journal. This is an Open Access article distributed under the terms of the Creative Commons Attribution License (CC BY 4.0)

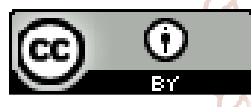

(http://creativecommons.org/licenses/ by $/ 4.0$ )

\section{Introduction:}

Making posterity is one of women most regarded accomplishments and delights. Over a large portion of a million women around the globe pass on amid pregnancy and childbirth (WHO, 2004). "Information of fetal size has two fundamental applications in obstetric practice. The first is to look at the size of an embryo of obscure gestational age with ordinary figures and so acquire a gauge of the development of the hatchling. The second application is to look at the size of an embryo of known gestational age with referred to ordinary either as a solitary perusing to tell whether the hatchling being referred to is bigger or littler than typical or, better, as a progression of readings. Ultrasonography imaging has emerged as the primary imaging modality for assessing the obstetric patient. Over the years, various radiologic imaging modalities have been used in pregnant women, but none can match the benefits of Ultrasonography; a relatively low-cost, real time imaging modality that doesn't involve ionizing radiation. (Carol .B. Benson\& Peter .M. Doubilet, 2014).

There are two reliable EFW formulas, both giving low deviations from actual birth weight and with low error of 7.7 and $7.9 \%$ across the weight ranges. (Had lock group formula B with parameters and the Had lock formula $\mathrm{C}$ with parameters) For all formula the highest random error occurred in the macrosomic group. The lowest random error in all weight groups was the Had lock B formula incorporating the HC/AC/FL (7.7\%). (Susan Campbell Westerway, 2012).A study by Esinler et al 2015, enrolled participants 495, calculated the fetal weight using 18 different formulas. The mean percentage error, the mean absolute percentage error and reliability analysis were used to compare the performance of the formula. This study concluded that Had lock I, Had lock's III and Ott may be used to predict the estimated fetal weight accurately in all fetuses in their study. Formula Ott, Had lock's IV and Coombs may be preferred to predict the fetal weight in fetuses $<2,500 \mathrm{~g}$, and $>4,000 \mathrm{~g}$. Better formulas should be developed to predict the fetal weight in fetuses $>4,000 \mathrm{~g}$. To describe the assessment of fetal weight using different formula with parameters (with the sample error), this study was undertaken.

Materials and Methods: This study was a prospective cohort study approved by ethics committee of the Maternity Hospital Southern region of Tamilnadu. Two hundred pregnant women admitted at full term for planned delivery either by elective caesarean section or by induction of labor. Mothers with live singleton fetus who had their gestational age confirmed by dates and ultrasound done before 22 weeks. All measurements will be taken within one week of 
delivery. If undelivered beyond this time interval the measurements will be repeated within 48 hours. Therefore Multiple gestations, Patient with polyhydraminos or oligohydramnios., Abnormal lie, Preterm labor, Fetal malformations, Antepartum hemorrhage, Eclampsia, Obese patients (>90kg), Uterine / ovarian mass complicating pregnancy were excluded.

Data Collection: Real time ultrasound scan, equipment Philip HD 7 was used to measure abdominal circumference (AC), Biparietal diameter (BPD), Head Circumference (HC), and femur length (FL). Consent: Prior to allocation, participants were counseled regarding the study, and explained that ultrasound which is a routine for obstetrics cases is a non-invasive and safe procedure. Consent was obtained in a designated form.

Research questions: was with regard to a. What would be the accuracy of antenatal assessment of fetal weight in pregnancies by using Johnson's formula, Had lock formula and Ultrasonography? B. Comparison of these different methods with the actual birth weight of these babies after delivery.
Statistical Analysis: After completion of the study, continuous data were analyzed and presented as mean \pm standard deviation, and categorical variables were presented as count and percentage. The clinical and Sonographic EFW were compared with the actual weight and accuracy of birth weight was determined by calculating: Mean of simple error (EFW-BW), Mean of absolute error (absolute value of [EFWBW]), Mean of absolute percentage error (\%) (Absolute value of [EFW-BW] x 100/BW), Radio (\%) of estimates within $10 \%$ of actual birth weight (true when absolute percentage error was not more than 10\%). Inferential Statistical analysis was performed using Chi Square test and Wilcoxon signed-rank test, $\mathrm{P}$ value $<0.05$ was considered as significant.

Results: Two hundred mothers were included in this study, Mean (SD) for maternal age was 24.48 (SD \pm 2.8 ) years, and for gestational age of participants was 38.9 (SD \pm 1.25 ) weeks. Descriptive statistics regarding variable birth weight is as below.

\begin{tabular}{|c|c|c|c|}
\hline Actual birth weight & Primigravida & Multigravida & \\
\hline$<2000$ gms & $62.9 \%$ & $37.1 \%$ & \multirow{5}{*}{$\mathrm{X} 2=11.205 \mathrm{df}=4 \mathrm{p}=0.024$} \\
\hline $2001-2500$ gms & $46.7 \%$ & $53.3 \%$ & \\
\hline $2501-3000 \mathrm{gms}$ & $44.8 \%$ & $55.2 \%$ & \\
\hline $3001-3500$ gms & $39.3 \%$ & $60.7 \%$ & \\
\hline$>3500$ gms & $40.0 \%$ & $60.0 \%$ & \\
\hline
\end{tabular}

\begin{tabular}{|c|c|c|c|c|c|c|}
\hline EFW (kg) & Had lock formula (N) & $\%$ & Johnson's formula (N) & $\%$ & Birth weight (N) & $\%$ \\
\hline $1.5-2$ & - & - & & & 3 & 1.5 \\
\hline $2-2.5$ & 7 & 3.5 & Develophnt 4 - & 2 & 23 & 11.5 \\
\hline $2.5-3$ & 55 & 27.5 & 63 & 31.5 & 88 & 44 \\
\hline $3-3.5$ & 91 & 45.5 & 81 & 40.5 & 64 & 32 \\
\hline $3.5-4$ & 46 & 23 & 42 & 21 & 17 & 8.5 \\
\hline$>4$ & 1 & 0.5 & 10 & 5 & 5 & 2.5 \\
\hline
\end{tabular}

The above table shows that majority of the birth weight were distributed between $2.5-3.5 \mathrm{~kg}$. P value for both Hadlock formula and Johnson's formula were 0.5 i.e. $>0.05$ which is not significantly correlated.

\section{Comparison of Mean weight of two formulae:}

\begin{tabular}{|c|c|c|}
\hline Formula & Mean birth weight in gms & S.D in gms \\
\hline Had lock & 3213.85 & 371.472 \\
\hline Johnson's & 3227.548 & 401.17 \\
\hline Birth weight & 3025.4 & 445.172 \\
\hline
\end{tabular}

The mean birth weight of Had lock formula is closest to the mean of actual birth weight. The data is detailed in the table given below.

\begin{tabular}{|c|c|c|}
\hline Actual birth weight in (gms) & Had lock formula & Johnson's formula \\
\hline $1500-2000 \mathrm{gms}$ & 231.6 & 268.5 \\
\hline $2001-2500$ & 294.9 & 293.7 \\
\hline $2501-3000$ & 316.0 & 314.1 \\
\hline $3001-3500$ & 330.6 & 331.7 \\
\hline $3501-4000$ & 357.0 & 363.8 \\
\hline$>4000$ & 339.0 & 396.8 \\
\hline
\end{tabular}

Percentage of Cases with Error in Grams which shows that there is no significant difference by finding out the frequency of closeness by specific method with respect actual birth weight. 
International Journal of Trend in Scientific Research and Development (IJTSRD) @ www.ijtsrd.com eISSN: 2456-6470

\begin{tabular}{|l|c|c|c|}
\hline \multirow{2}{*}{ Error(gms) } & \multicolumn{3}{|c|}{ Percentage of cases. } \\
\cline { 2 - 4 } & Dare's & Johnson's & USG -Had lock's \\
\hline Up to 150 gms & $45.2 \%$ & $33.3 \%$ & $27.7 \%$ \\
\hline Up to 250 gms & $68.2 \%$ & $57.1 \%$ & $59.4 \%$ \\
\hline Up to 350 gms & $84.7 \%$ & $70.8 \%$ & $84 \%$ \\
\hline Up to 450 gms & $96.1 \%$ & $87.5 \%$ & $96.6 \%$ \\
\hline Up to 550 gms & $98.5 \%$ & $94.9 \%$ & $99.4 \%$ \\
\hline
\end{tabular}

As there is no significant difference between the mean weights of two formulae, percentile error was calculated as shown below: Calculated using the formula Percentile error=mean error/actual birth weight $\times 100$.

\begin{tabular}{|c|c|c|c|c|}
\hline $\begin{array}{c}\text { Percentile } \\
\text { Error } \%\end{array}$ & Had lock's Formula & $\%$ & Johnson's Formula & $\%$ \\
\hline 5 & 65 & 32.5 & 60 & 30 \\
\hline 10 & 46 & 23 & 50 & 25 \\
\hline 15 & 18 & 9 & 29 & 14.5 \\
\hline 20 & 25 & 12.5 & 20 & 10 \\
\hline 25 & 20 & 10 & 10 & 5 \\
\hline 30 & 11 & 5.5 & 11 & 5.5 \\
\hline$>35$ & 15 & 7.5 & 20 & 10 \\
\hline
\end{tabular}

\begin{tabular}{|c|c|c|c|}
\hline Methods & $\begin{array}{c}\text { Mean simple } \\
\text { error } \pm \text { SD }\end{array}$ & $\begin{array}{c}\text { Mean absolute } \\
\text { error } \pm \text { SD }\end{array}$ & $\begin{array}{c}\text { Mean absolute percentage } \\
\text { error Mean } \pm \text { SE }\end{array}$ \\
\hline Dare's formula & $84.8 \pm 218$ & $18 \pm 14$ & $9.0 \pm 0.18$ \\
\hline Johnson's formula & $157.4 \pm 258$ & $24 \pm 17$ & $10.2 \pm 0.27$ \\
\hline USG - Had lock's & $148.5 \pm 216$ & $23 \pm 12$ & $7.4 \pm 0.20$ \\
\hline
\end{tabular}

Absolute simple error $=$ estimate - actual birth weight.

Standardized absolute error $=$ (value of absolute simple error/actual birth weight $) \times 100$.

$\mathrm{SD}=$ standard deviation. The above mentioned table denotes the accuracy of birth weight of the babies by three methods of antenatal fetal weight estimations, calculated by comparing their Mean simple error, mean absolute error and mean absolute percentage error. Paired t test were used to assess their accuracy in terms of correlation coefficient with the actual birth weight.

\begin{tabular}{|c|c|c|}
\hline Methods & Mean simple error & Correlation coefficient \\
\hline Dare's formula & $84.8 \pm 218=647$ & 0.878 \\
\hline Johnson's formula & $157.4 \pm 258$ & 0.829 \\
\hline USG - Had lock's & $148.5 \pm 216$ & 0.893 \\
\hline & & \\
\hline
\end{tabular}

\section{Discussion:}

The mean simple error is least in Dare method than USG but when correlation coefficient was calculated in different methods, it was evident that USG seems to be correlating well with actual birth weight than Dare's and Johnson's methods which seems to be least correlated and this correlation was statistically significant. After applying wilcoxon rank sum test to the mean absolute percentage error of Dare's formula and ultrasound methods, the difference among the mean absolute percentage errors of these two methods were statistically significant. Hence antenatal assessment of the birth weight of the babies is

more accurate with USG method followed by clinical estimation of the birth weight by Dare's formula. When compared with normal birth weight babies estimated within the $10 \%$ of actual birth weight by different methods with large for gestational age babies from the above table it is evident that it is statistically not significant.

Fetal weight estimation using a measuring tape applied to two different clinical formulas was as accurate as ultrasound estimates for predicting the infant's actual birth weight within $10 \%$.Although the results of our study revealed that the accuracy within $10 \%$ of actual birth weight in Dare's clinical estimated fetal weight was slightly higher than sonographic estimated fetal weight followed by Johnson's formula of estimating fetal weight $(67.3 \%, 62.7 \%$ and $59.9 \%$ respectively) but the difference of the accuracy was insignificant and this is similar with the previous studies by, Maria RT et al who correctly estimated the actual birth weight within $10 \%$ in $61 \%, 57 \%$ and $65 \%$ of the cases using two clinical formulas (Johnson's formula and Dare's formula) and ultrasound estimate, respectively. In our study, mean absolute percentage error is $9.0 \pm 0.18,10.2 \pm 0.27$ and $7.4 \pm 0.20$ for Dare's formula, Johnson's formula and ultrasound - Had lock's formula respectively which clearly shows ultrasound estimation is more accurate in the fetal weight estimation.

The correlation coefficient for the various methods in present study when compared with actual birth weight were 0.878, 0.829 and 0.893 for Dare's formula, Johnson's formula and ultrasound-Had lock's formula respectively. A study by Moigan Kalantari et al 2013 correlated with our study in exploring a new formula for estimating fetal weight, which also showed that adding STT to other variables (BPD and FL) in predictive models of fetal weight would provide the best estimation $\left(r^{2}=0.77\right)$ and the predictive strength of each 
formula using STT or AC along with BPD and FL would be the same $\left(r^{2}=0.7\right)$

The result shows that the mean birth weight of Had lock is closest to the mean of actual birth weight in comparison with the Johnson's formula. But there is no significant difference between mean of Had lock and Johnson formulae. The mean of Had lock is $3213.85 \pm 371.472$ grams and the mean weight of Johnson is $3227.548 \pm 401.1$ gms. The result shows the $p$ value obtained for the mean birth weight of Had lock formula and Johnson's formula which is $<0.01$.This indicates that both formulae are highly significant in obtaining the mean birth weight but not when taken individually. The mean error of the Had lock formula is least because Had lock formula uses four parameters and Johnson's formula uses only one parameter (SFH) for estimating fetal weight. The mean error of Johnson formula is 202.148gms and the mean error of the Had lock formula is 188gms Percentile error of $<20 \%$ is $77 \%$ in Had lock formula compared to $79 \%$ in Johnson's formula. Percentile error of Johnson's formula. The fetal weights are overestimated between $1.5-2.5 \mathrm{~kg}$ birth weights. Overestimation is more in Johnson's formula because that is influenced by the maternal obesity and liquor volume. Between 2.5 - $3.5 \mathrm{Kg}$ estimation is en par with actual birth weight.

\section{Conclusion:}

This study was undertaken at the Institute of obstetrics and gynecology, hospital in southern region of Tamilnadu to compare the various methods of fetal weight estimation at term pregnancy among200 patients with singleton pregnancy. The cases were randomly selected and detailed obstetrical history was taken. The gestational age of all the patients was known and all the cases delivered within one week of measurement. Fetal weight was estimated by using different formula and was compared to the actual weight of the baby taken immediately after birth and a comparative analysis was done. Of the 200 cases, $45.4 \%$ were primigravida and $54.6 \%$ were multigravida. Most of the women were in the average reproductive age group of 20-30 years. Most of the patients had normal vaginal delivery (53.9\%) and $39.7 \%$ delivered by lower segment caesarean section. The sex distribution of the babies in the study population showed that more male babies were born. Majority of the babies at birth weighed between 2501-3000 gms. In the study population, more primigravida delivered babies with very low birth weight and more multigravida delivered babies of birth weight $>3500$ gms.

Johnson's and ultrasound-Had lock's formula had a marked tendency to overestimate the fetal weight. Error was within 350 gms in $84.7 \%, 70.8 \%$ and $84 \%$ of cases by Dare's, Johnson's and ultrasound-Had lock's formula. The mean simple error and the mean absolute error was least by Dare's formula followed by ultrasound-Had lock's and Johnson's formula. The mean absolute percentage error was least by ultrasound - Had lock's formula followed by Dare's formula and Johnson's formula. The coefficient correlation calculated for different methods showed that ultrasound seems to be correlating well with actual birth weight than Dare's and Johnson's formula. The estimates within $10 \%$ of actual birth weight were $67.3 \%, 62.7 \%$ and $59.9 \%$ with Dare's, Johnson's and ultrasound-Had lock's formula which was not statistically significant. Antenatal assessment of birth weight by ultrasound seems to be better for estimating low-birth weight babies and for large for gestational age babies.
The clinician's estimate using the palpation method is by far the most accurate in any age of gestation, followed by Johnson's Method, and the Modified Johnson's Method with the least accurate estimate. At 34-37 weeks age of gestation, the palpation method had the closest estimate. At 37 weeks age of gestation and above, the Dare's Method is more superior. Experience affects clinical estimate when using abdominal palpation, the values obtained by senior residents were noted to be closer to actual compared to second and third year residents. The Johnson's Method, Dare's Method and the Modified Johnson's Method however are not affected by experience. Although it can be observed that estimates are closer in patients with lower BMI, this was not statistically significant.

Clinical estimation of birth weight may be as accurate as routine ultrasonography estimation, except in low-birthweight babies. From our study, it can be concluded that antenatal fetal weight can be estimated with considerable accuracy by abdominal girth, symphysio-fundal height and ultrasound Had lock's formula. Abdominal girth, symphysiofundal height is simple, inexpensive and of immense value in developing country like ours, hence it can be used anywhere even by domiciliary midwives to predict fetal weight. Accuracy of Johnson's formula was less than abdominal girth $\mathrm{x}$ symphysio-fundal height and ultrasound - Had lock's formula.

\section{References:}

[1] Esinler D. Bircon O., Sahin E.G., Kandemir O., Yalvac S., 2015, finding the best formula to predict the fetal weight: Comparison of 18 formulas, Vol 18, No 2.

[2] Susan Campbell Westerway, 2012, Estimating fetal weight for best clinical outcome, Australian Journal of Ultrasound in Medicine. 15(1), 13 to 17.

[3] Carol.B. Benson\& Peter .M. Doubilet, 2014, the history of imaging in obstetrics, Radiology, RSNA Journals, Vol 273.

[4] O'Conner C, Farah N, O'Higgins A, Segurado R, Fitzpatrick C, Turner MJ, et, al. 2013, Longitudinal measurement of fetal thigh soft tissue parameters and its role in the prediction of birth weight. Prenatal Diagnosis. 28:1-7.

[5] Lee W, Deter R, Sangi-Haghpeykar H, Yeo L, Romero R. 2013, Prospective validation of fetal weight estimation using fractional limb volume. Ultrasound obstetGynecol.;41:198-203

[6] IssabelleMonnier, Annie Ego, Alexandra Benachi, Pierre-Yves Ancel, JenniferZeitlin, 2018, comparison of the Had lock and INTERGROWTH formulas for calculating estimated fetal weight in a preterm population in France, American journal of Obstetrics and Gynecology, Volume 219, Issue 5.

[7] Kumari A, Goswami S, Mukherjee P. 2013, Comparative study of various methods of fetal weight estimation in term pregnancy, Journal of south Asian federal obstetrics and gynecology. 5(1), 22-25.

[8] Moigan Kalantari, Arizou Negahdari, Shima Roknsharifi, Mostafa Oorbani, 2013, A new formula for estimating fetal weight, Iranian Journal of Reproductive medicine, 11(11), 933-938. 